\title{
Masculinidades en la industria del software en Argentina ${ }^{1}$
}

\author{
Hernán M. Palermo ${ }^{2}$ \\ Centro de Estudios e Investigaciones Laborales (CEIL-CONICET-Argentina) \\ hernanpalermo@gmail.com
}

Resumen: En el año 2017 iniciamos una investigación en empresas de procesos productivos vinculados con el software en Argentina. Algunos autores sostienen que las formas organizativas de trabajo caracterizadas como toyotistas o posfordistas encuentran su más acabada expresión en la industria del software. En este sentido, se postula la idea de una sociedad posindustrial a raíz de las tecnologías digitales. Otros, en cambio, plantean que nos encontramos inmersos en una nueva etapa denominada «capitalismo informacional». En el marco de esta industria, nuestro propósito para este artículo es indagar en las formas de construcción de un perfil de trabajador, retomando la premisa de que las políticas empresarias dinamizan nociones que configuran posiciones de género. En tal sentido, pretendemos desentrañar $y$ problematizar la significación alrededor de las nociones de género en la industria del software, para comprender las estrategias de poder que se despliegan en estos espacios de trabajo donde las empresas son actores activos en la construcción de una hegemonía empresaria. Específicamente, nos interesa abordar la particular noción de masculinidad que se construye, dado que se trata de un trabajo en el que no bace falta el esfuerzo físico, la resistencia, la fortaleza, tal como sucede en otras actividades. Por el contrario, predomina una «cultura joven» siempre renovada y por momentos infantilizada. La vinculación profunda con la tecnología demanda «jóvenes talentosos», entendiendo que la idea de joven no se ancla univocamente en la edad vital de un trabajador. En tal sentido, ballamos que en la industria de

1 Quiero agradecer a la antropóloga Gabriela Llamosas por los intercambios y debates alrededor del mundo laboral de la industria del software, discusiones que forman parte indudable de este primer escrito que aquí presento.

2 Doctor en Ciencias Antropológicas. Investigador del Centro de Estudios e Investigaciones Laborales (CEILCONICET-Argentina). Director de la Revista Latinoamericana de Antropología del Trabajo, perteneciente al CEIL de Argentina y al CIESAS de México. 
software no solo operan nociones no tradicionales acerca de la masculinidad, sino que podemos afirmar que la consolidación de una particular disciplina fabril fortalece una masculinidad no hegemónica, acorde a las necesidades del proceso de trabajo. Nuestra propuesta, en cierta forma rara avis, es situar la mirada en los trabajadores hombres en la industria del software y analizar la relación entre masculinidad y disciplina fabril.

Palabras clave: Masculinidades; industria del software; disciplina fabril.

\section{Masculinities in the software industry in Argentina}

\section{$\mathrm{Abstract}^{3}$}

In the year 2017 we initiate a research in companies of productive processes linked with software in Argentina. Some authors support that the organizational forms of labour characterized as Toyotist or post-Fordist find their more elaborate expression in the industry of software. In the frame of this industry, our intention for this paper is to investigate the construction forms of the worker's profile, taking again the assumption of which the business policies invigorate notions that make up gender positions. To this respect, we try to uncover and to problematize the meaning around the notions of gender in the industry of software, for understanding the power rules which are deployed in these labour areas where the companies are active actors in the buildingup of the business hegemony. Specifically, we are interested in approaching the particular notion of masculinity that is constructed, provided that it is a labour in which is not required the physical effort, the resistance, the strength, as happens in other activities. On the contrary, prevail a "young culture" always renewed and for moments infantilizated. To this respect, we find that in the industry of software not only operate notions not traditional regarding masculinity, but also that we could affirm that the consolidation of a particular industrial discipline stregthens a not hegemonic masculinity, according to the needs of the labour process. Our proposal, is to place the gaze into the male workers in the industry of software and to analise the relationship between masculinity and industrial discipline.

Keywords: Masculinities; software industry; industrial discipline.

3 Traducción de Julieta Mira (Ceil-CONICET). 
- Soy un malcriado, la empresa te malcría.

Pregunta: — ¿Qué te lleva pensar que sos un malcriado?

-Y..., que pido la computadora que quiero y me la consiguen, si quiero ir al gimnasio, me lo pagan... Tenés descuentos en Megatlon y esas cosas. O querés, bueno, yo tocaba un poco la guitarra: hay un cuartito muy cómodo que tienen un par de guitarras. Como que la parte de beneficios... funcionaba muy bien.

Trabajador de Google Argentina

\section{Introducción}

En el año 2017 iniciamos una investigación en empresas de procesos productivos vinculados con el software en Argentina. Algunos autores sostienen que las formas organizativas de trabajo caracterizadas como toyotistas o posfordistas —entre otras denominaciones similares - encuentran su más acabada expresión en la industria del software (Erbes, Robert y Yoguel, 2004; Mochi Alemán, 2003; Míguez, 2010; etc.) Es decir, aquellas formas «novedosas» que fueran analizadas en el clásico texto Pensar al revés por el intelectual francés Benjamín Coriat (1991) encontrarían su mayor desarrollo y esplendor en esta industria innovadora. Algunas formas organizativas se constituyen en ejemplos paradigmáticos en esta industria, como es el trabajo en equipo, en el que muchas veces los miembros de un equipo ni siquiera están físicamente en el mismo continente a raíz de las posibilidades que habilitan los avances tecnológicos. En este sentido, en la década de los setenta, algunos autores postularon el advenimiento de la sociedad posindustrial (Bell, 1976) producto de las tecnologías digitales. Otros, en cambio, han planteado que estamos inmersos en una nueva etapa denominada «capitalismo informacional» (Castells, 2006); hay quienes en esta misma sintonía hablan de «capitalismo digital» (Schiller, 2000), o de la era del «trabajo informacional» (Zukerfeld, 2012). Desde la antropología se plantea la expresión de «capitalismo electrónico informático» (Ribeiro, 2017). Todas estas nociones se encuentran influenciadas por las implicancias directas en los procesos productivos de las tecnologías digitales y la producción de bienes informacionales ${ }^{4}$. En definitiva, lo que se intenta señalar es que las «fábricas de software» plasman tendencias hegemónicas en las formas de producir cada vez más consolidadas y extendidas. La Meca del capitalismo electrónico informático y sus formas de organizar el trabajo está sin lugar a dudas en el norte de California, en EE. UU.: Silicon Valley. Este valle es un gran faro para todas las empresas de software en el mundo.

4 Bienes informacionales son aquellos bienes hechos de información digital. Hacemos referencia a bienes que se producen por ejemplo con una PC y están hechos puramente de bits: textos, programas de computadora, comunicaciones digitales, audio, entre otros. 
Más allá de cuántas rupturas o continuidades contengan las formas organizativas del trabajo en esta industria, lo que podemos señalar a partir del trabajo de campo realizado es que cuando se entra a una empresa de software se percibe rápidamente cierta atmósfera que podemos denominar a priori como «joven» y/o «descontracturada». Se trata en general de espacios coloridos, lúdicos, (pos) modernos y «livianos». Siempre hay una supuesta laxitud y libertad de los trabajadores respecto de la jornada de trabajo (se podría elegir «libremente» trabajar en la casa). Es un universo en el que se multiplican las palabras en inglés y se instituye una supuesta horizontalidad en las escalas jerárquicas, producto del trabajo en equipos interconectados. Inclusive los ceos de las empresas se presentan como uno más dentro de los equipos de trabajo. Entonces, a priori, parecen diluirse las órdenes, las jerarquías, las presiones y los conflictos: todo esto posibilitado por la tecnología siempre omnipresente. A tal punto se presentan como espacios sin conflictos que no son necesarias las «viejas» organizaciones gremiales, tal como nos aclaró una gerente de recursos humanos de una empresa importante de producción de flujos de información digital. La misma gerente, al preguntarle cómo eran «las sanciones» a los trabajadores por incumplimientos, respondió: «No, no usamos esas palabras... Acá es todo muy humanístico. Si un chico se manda alguna macana se habla, se investiga. Se ve muy raro eso, tenés una visión muy fabril». La acusación a nuestra mirada resulta interesante ante un espacio de trabajo que intenta construirse de forma radicalmente opuesta a un establecimiento de características fabriles. No obstante, nos llama profundamente la atención la referencia a los trabajadores como «chicos»: esto cobra aún más relevancia si lo comparamos con otros espacios laborales.

En el marco de este planteamiento, mucho se ha dicho acerca de este nuevo sistema de extracción de ganancias basado en el conocimiento, la innovación y la creatividad como factores de acumulación, pero poco se ha escrito acerca de las necesidades de estos procesos productivos de producir y reproducir una particular fuerza de trabajo. Los nuevos modelos gerenciales ponen en práctica otros discursos acerca del trabajo, los trabajadores y la relación entre estos y las empresas. En este contexto, retomar la premisa fundamental - que las políticas empresarias dinamizan nociones que configuran posiciones de género en los trabajadores (Palermo, 2017) - nos permite comprender las estrategias de poder que se despliegan en estos espacios de trabajo donde las empresas son actores activos en la construcción de una hegemonía empresaria (Palermo, 2012). La pretensión hegemónica consiste en que la doctrina empresaria devenga «cultura», es 
decir, disciplina ${ }^{5}$. Toda disciplina fabril se estructura alrededor de determinadas concepciones de género.

En estas fábricas de «bienes informacionales» se configura una particular construcción acerca de la masculinidad ${ }^{6}$, dado que es un trabajo en el que no hace falta el esfuerzo físico, la resistencia, la fortaleza, tal como puede observarse en otras industrias. Por el contrario, predomina una «cultura joven» siempre renovada y por momentos infantilizada. La vinculación profunda con la tecnología demanda «jóvenes talentosos», pero la idea de joven no se ancla unívocamente en la edad vital de un trabajador. Las empresas seducen a esos trabajadores no solo por los salarios - que en algunos casos son bajos en comparación a los de otros empleos - sino por las políticas de beneficios que otorgan a sus empleados.

Para analizar este aspecto, nos inspiramos en los abordajes de género y en particular en las investigaciones sobre masculinidades. En este sentido, uno de los aportes de estas investigaciones es que, cuando hablamos de prácticas y representaciones vinculadas a la masculinidad, debemos hacerlo entendiendo que no existe una forma fija e inflexible. Por el contrario, encontramos múltiples maneras de comportarse como hombres (Gilmore, 1994; Laqueur, 1994; Kimmel, 1997; Connell, 1995). Incluso el patrón de «dominación patriarcal» encuentra matices, zonas grises y contradicciones que tensionan ese modelo (Bastos, 1998). Retomando esta última propuesta analítica, hallamos que en la industria del software no solo operan otras nociones no tradicionales acerca de la masculinidad, sino que podemos afirmar que la consolidación de una particular disciplina fabril fortalece elementos de una masculinidad no patriarcal, acorde a las necesidades del proceso de trabajo. Nuestra propuesta, en cierta forma rara avis, es situar la mirada en los trabajadores hombres en la industria del software y analizar la relación entre masculinidad y disciplina fabril. En la industria del software no solo no se produce una exacerbación de la masculinidad, sino que se dinamizan nociones acerca de la «juventud» en los trabajadores hasta el punto de producir un imperativo de masculinidad infantilizada. Esta es una de las claves por donde transitará el análisis de este artículo.

Para realizarlo, nos basamos en un trabajo de campo de un año, en particular en dos grandes empresas transnacionales de software: Google y Mercado Libre ${ }^{7}$.

5 Hemos desarrollado en publicaciones anteriores la idea de disciplina fabril para dar cuenta de los procesos que nutren la hegemonía empresaria. Una de las caras de la disciplina son los procesos coercitivos y su anverso, la interiorización de prácticas y representaciones a partir de la creación y consolidación de consensos legitimados en el interior de los espacios de trabajo.

6 Para Connell (1995), la masculinidad es un ordenamiento social e histórico en el que un hombre se compromete en una posición de género.

7 Google es una de las empresas más grandes del mundo, de capitales estadounidenses, fundada en 1998. Por su parte, Mercado Libre es una gran empresa argentina, que transnacionalizó su capital a toda Latinoamérica, fundada también a finales de la década del noventa. 
Ambas se sitúan en barrios de la Ciudad Autónoma de Buenos Aires no industriales, lo que refuerza su imagen e identidad antagónicas con una fábrica ${ }^{8}$. La metodología y técnicas que sustentan la presente investigación recuperan una perspectiva cualitativa, centrada en el enfoque etnográfico (Achilli, 2005). Este abordaje nos permitió captar la diversidad de situaciones y prácticas encarnadas en los sujetos sociales, en cuanto prácticas que implican representaciones respecto de las condiciones externas en las que dichos sujetos desarrollan su vida cotidiana. El enfoque etnográfico resulta a nuestro entender una herramienta que contribuye al análisis de la cotidianeidad, la particularidad, o como solemos decir, las historias al «ras del suelo». En tal sentido, hemos realizado entrevistas en profundidad a trabajadores varones profesionales, con excepción de la gerente de recursos humanos de Mercado Libre, la única mujer entrevistada al momento. Para el caso de esta empresa, hemos entrevistado a trabajadores de dos equipos de trabajo y de todas las categorías laborales: analista junior, semisénior, sénior, proyect líder y top mánager. En este caso fueron 15 entrevistas a varones con edades de entre 27 a 38 años. Para la empresa Google, hemos entrevistado a ingenieros y programadores, un total de 10 entrevistas con edades similares al caso de Mercado Libre. Las entrevistas fueron realizadas a partir de guías temáticas dirigidas a recuperar material espontáneo que resulte de la interacción con el entrevistado, en el que se puedan incluir temas, percepciones y valoraciones propias. También realizamos una entrevista grupal a uno de los equipos de Mercado Libre. Por otra parte, resultó ser una estrategia privilegiada para la investigación la «observación participante». Para entender a qué nos referimos con «observación participante», seguimos los planteamientos interesantes de Guber (2001), la cual argumenta que dicotomizar la «observación» de la «participación» es caer en una perspectiva positivista que sitúa al investigador o investigadora en un lugar neutral. Estar en el «escenario social», nuestra sola presencia allí, está implicando una «participación». Y esa interacción enmarcada en un enfoque analítico determinado le brinda al antropólogo o antropóloga material imprescindible para el análisis.

\section{Masculinidades posfordistas}

Lo primero para resaltar de esta industria es la frontera que se demarca entre aquellos que trabajan como desarrolladores y aquellos que no. Los desarrolladores o programadores producen el «bien informacional»: son los trabajadores principales del proceso productivo. El desarrollo de software puede ser de pro-

8 Las oficinas de Google se encuentran en el lujoso barrio de Puerto Madero. Mercado Libre tiene varias oficinas en Argentina: las dos más importantes están en la provincia de Córdoba y en la Ciudad Autónoma de Buenos Aires, en el barrio de Saavedra. También tiene oficinas de menor tamaño en la provincia de San Luis y en el barrio de Parque Patricios, en la ciudad de Buenos Aires. 
ductos estándar, de productos personalizados y únicos para una empresa, servicios, etc. Conforme a la apreciación del investigador, la variedad existente bajo el rótulo de software resulta abrumadora y difícil de comprender, a partir de la producción y sus posibilidades casi ilimitadas. Después encontramos una variedad de otros procesos secundarios que van desde el marketing del producto, la venta, la implementación del producto informacional, el soporte técnico de esos productos, atención al cliente, etc. Google en Argentina no produce software, sino que básicamente realiza diversas tareas de soporte técnico a clientes en toda Sudamérica ${ }^{9}$. Mercado Libre es en sí una plataforma virtual que conecta vendedores con compradores en un mercado virtual en toda Latinoamérica. Esta empresa sí produce software en Argentina.

Contrariamente a lo que sucede con otros rubros vinculados a procesos tecnológicos y de innovación, los trabajadores en esta industria, incluidos los desarrolladores de software, no cuentan necesariamente con credenciales provenientes de la educación formal, y entre ellos no valoran - como ocurriría en otros trabajos - las credenciales universitarias al momento de describir dónde han aprendido su saber profesional. Ser autodidacta y emprendedor son las formas más comentadas para el acceso a los saberes profesionales propios de esta industria, en particular entre desarrolladores ${ }^{10}$. Un programador con responsabilidad de mando en Mercado Libre y uno de los selectores de los nuevos desarrolladores nos relataba lo siguiente:

El mundo del desarrollo es peculiar, porque vos podés terminar el secundario, ser un crack programando, que venís programando por intuición propia desde los diez años porque te interesó, porque entraste a Internet, te bajaste un programa y empezaste a desarrollar... Sos crack y claramente vas a conseguir trabajo y vas a hacer lo mismo que un universitario con posgrado y máster. Normalmente es así. Generalmente buscamos gente que tenga formación académica, pero si viene alguien con mucho potencial que no tiene título, como nos pasa muy seguido, claramente es una persona que incorporamos a la empresa. El tema de tecnología y desarrollo es muy particular en ese caso. Es normal encontrar gente muy, muy buena y no tiene estudios profesionales... Hace muy poquito contratamos una persona que nunca, nunca estudió, pero nada, ni siquiera un taller de

\footnotetext{
9 Por ejemplo, todo lo que está vinculado a publicidad en las plataformas correspondientes a Google, servicios de productos para empresas como páginas web, aplicaciones que contabilizan diversas situaciones de las empresas, servicio de mailing interno y otros productos gratuitos.

10 Algunos han atravesado procesos de formación formal, pero abundan aquellos que no lograron concluir las carreras universitarias. Para las empresas de software esta situación no resulta una restricción. Dughera, Segura, Yansen y Zukerfeld (2012) plantean que la formación universitaria no constituye un factor determinante; no obstante, tampoco es irrelevante para el desarrollo de las capacidades de los trabajadores de la industria del software.
} 
programación. Y es un crack, o sea, claramente la rompe porque siempre se interesó de chiquitito en la programación (sénior mánager, Mercado Libre, 2017).

La titulación formal no está relacionada directamente con la posesión de los saberes técnico-profesionales que exigen las actividades de programación y para las empresas tampoco resulta un impedimento no poseerla.

Otra característica elocuente de los desarrolladores y ampliamente investigada es que son en su mayoría varones. Esto contrasta con el hecho de ser una industria relativamente reciente en comparación con otras actividades, y más aún en Argentina, donde su fomento y crecimiento se remonta a $2003^{11}$. Algunos autores, al intentar dar respuesta a esta situación, plantean que la escasa participación de mujeres como desarrolladoras se debe a diversas cuestiones: por un lado, el acceso diferencial entre hombres y mujeres a la tecnología como actividad lúdica desde la más temprana infancia, sobre todo en lo que se relaciona con videojuegos (Mura, Yansen y Zukerfeld, 2012); también sucede que las empresas estructuran puestos diferenciados genéricamente, donde las mujeres acceden a lo que es atención a los clientes o soporte técnico, que implica en cierta forma atención al cliente. Por otra parte, el trabajo de desarrollador es una actividad con una alta rotación. Esta característica es un problema para aquellas mujeres que eligen la maternidad en algún momento de sus itinerarios de vida.

Lo que no ha sido indagado aún en profundidad $-y$ no pretendemos agotarlo aquí- son las representaciones masculinas que se dinamizan en los espacios de trabajo de la industria del software, que son complejas y variadas, al punto de desmontar algunos importantes elementos icónicos del modelo patriarcal. Las empresas vinculadas a este rubro también suelen presentarse en ese sentido como rupturistas respecto de los moldes tradicionales, aunque como vimos siguen prefiriendo varones en los puestos de desarrolladores y son ellos los que son «cracks programando». En estos ámbitos de trabajo persiste un ethos de la masculinidad apropiado y ejercido por los trabajadores del software, el cual trastoca modelos tradicionales, no obstante robustece una particular disciplina fabril.

Pregunta: ¿Cuál es la tarea del jefe de equipo?

Respuesta: El jefe de equipo no solo maneja el tema de programación, sino que tiene que tener soft skills para poder manejar los grupos... Skills blandos. Tiene que saber relacionarse con las personas, gestionar, liderar, saber hacer, dar lo mejor de su equipo no solo haciendo un buen seguimiento y planificación, sino que

$11 \mathrm{El}$ fortalecimiento inicial del sector informático en Argentina está asociado a las políticas de desarrollo de sustitución de importaciones en articulación con el crecimiento de instituciones científicas. Es desde el año 2003 que se observa en Argentina un crecimiento del sector del software (Montes Cató, 2010). Este proceso se explica por el cambio en el patrón de acumulación al producirse el abandono de la valorización financiera y fortalecer la producción de bienes, en particular aquellos provenientes de la rama industrial. 
tiene que saber muy bien qué piensa y siente su equipo. Nadie puede guardarse nada. Si un integrante del equipo está angustiado, el jefe de equipo debe poder hacer que lo diga, que lo exprese. Pensá que los objetivos de trabajo se arman por equipo, se definen colectivamente. Nosotros cada tres meses nos juntamos a definir objetivos. Nos juntamos y definimos todo lo que vamos a hacer, cuáles son todos los proyectos que vamos a ejecutar durante los próximos tres meses. Cuando terminan los tres meses, se hace una evaluación a cada uno de los proyectos, de 1 a 5: 3 es que cumplió el objetivo, 4 es que hizo un poco más de lo que se pidió y 5 que fue excelente, 2 y 1 , que no cumplió el objetivo (sénior mánager de Mercado Libre, 2017).

El relato expresa de forma detallada las cualidades que debe tener un jefe de equipo. Claramente este puesto resulta ser un engranaje clave en el proceso productivo del software, porque es el que lleva adelante la coordinación de los proyectos y el manejo de los grupos. Míguez lo sintetiza de la siguiente manera: «La operación de coordinar diferentes recursos en la búsqueda de un objetivo determinado y por un periodo de tiempo limitado justifica la aparición de la figura de los líderes del proyecto» (2010:62). El trabajo interconectado en pequeños equipos es la columna vertebral de la organización del trabajo en la producción del software. Estos equipos constan de un uso fluido de tecnología de información y una importante formación profesional. Y la otra característica fundamental es la «creatividad» como motor de la producción. Esta característica del proceso productivo «tensiona» a las empresas en el marco de un alto grado de aleatoriedad e incertidumbre. El trabajo está indisociablemente atado a la «creatividad», y en tal sentido está sujeto a mayores errores y vicisitudes que otros trabajos, y sobre todo a un difícil control en los tiempos de producción. La formulación de Braverman - «el capitalista cuando compra y consume fuerza de trabajo los cálculos están lejos de ser tan precisos y exactos» (1974:75) - encuentra su más acabada expresión en esta industria creativa. De ahí la importancia que adquiere el jefe de equipo en el proceso, dado que no solo requiere de un profundo saber técnico profesional, sino también de lo que se denomina cotidianamente en esta industria soft skills ${ }^{12}$. Estos son «saberes blandos» que se encuentran orientados - sobre todo- al manejo de los equipos. En este fragmento que seleccionamos se evidencia una de las cualidades fundamentales que un jefe de equipo debe tener: saber qué «piensan»y qué «sienten» los integrantes de su equipo. Es información vital para la correcta planificación creativa y colectiva, y para la concreción de los objetivos. A partir de los proyectos que encaran los equipos se consensuan objetivos trimestrales, definidos colectivamente. Luego se

12 Para la adquisición de los soft skills sí se valora la formación universitaria. Sobre todo para los puestos de mando es frecuente encontrar graduados de la Universidad Tecnológica Nacional (UTN). 
fragmentan esos grandes objetivos en pequeños objetivos semanales o planning semanal, para poder así configurar tareas relativamente cortas, permitiendo que semana a semana se plasmen resultados concretos y objetivables. Todo este proceso es visualizado en tiempo real por todos los integrantes del equipo a través de las posibilidades de control que brinda la tecnología en sus diversas plataformas. En términos de Castillo (2007), estos contextos de alta tecnología permiten la circulación y la puesta en común de una intervención sobre un programa rompiendo toda barrera física e incluso geográfica. Este esquema de trabajo somete a los trabajadores a un importante desgaste psíquico dado los altos niveles de presión que genera este panóptico digital, exponiéndolos a grandes altibajos emocionales. No resulta casual que en el fragmento de entrevista se hable de «angustia». Este punto es sumamente interesante. En oposición a un imperativo tradicional o patriarcal de masculinidad, donde la represión de las emociones resulta ser la condensación de un hombre «hecho y derecho» (Kazandjian, 2017), en estos espacios de trabajo se interpela a los varones a no bloquear los sentimientos y sobre todo a objetivarlos. Se demandan hombres expresivos. Este aspecto es paradójico y sugestivo para el análisis. Al fortalecer un ethos de masculinidad que robustece una disciplina fabril, se desmontan a la vez núcleos de sentidos de una masculinidad «tóxica» fuertemente arraigada en nuestras sociedades occidentales. No obstante, desmontar estas prácticas y representaciones de una masculinidad tradicional o tóxica, que como plantea Bourdieu vuelve a los varones prisioneros y víctimas de un modelo dominante (2012: 67), no libera a los hombres del sufrimiento al que son sometidos por un proceso de trabajo que demanda otras formas de masculinidad, incluso no tradicionales. Dadas las características de los procesos de producción de software, donde la creatividad juega un papel central, se presenta la dificultad empresarial de establecer mecanismos flexibles para la organización del trabajo. En tal sentido, se dificulta la determinación previa de los plazos de cumplimiento del trabajo, por ello se apela a formas de masculinidad acordes con los requerimientos de la producción, y el jefe de equipo se constituye como una de las poleas principales de transmisión de la dinámica laboral.

Para finalizar, podemos afirmar que en la fábrica del software se interpelan configuraciones masculinas que amplían los modelos hegemónicos, aunque no obstante conservan algunos sentidos vinculados a estos últimos, dado que aquel que siente angustia por las presiones laborales tiene que expresarlo y superarlo para poder continuar en su puesto de trabajo. Y los cracks terminan siendo en general desarrolladores varones. 


\section{Masculinidades infantilizadas}

El hombre ejerce la masculinidad en plural y de acuerdo al contexto en el que se encuentre. En este recorrido, indudablemente se destacan autoras como Joan Scott, quien al preguntarse «¿Cómo podemos explicar [...] las persistentes asociaciones de la masculinidad?», responde de la siguiente manera: «No creo que podamos hacerlo sin prestar atención a los sistemas simbólicos, esto es, a las formas en que las sociedades representan el género, hacen uso de este para enunciar las normas de las relaciones sociales o para construir el significado de la experiencia. Sin significado, no hay experiencia; sin procesos de significación no hay significado» (2008: 282). Esta línea argumental nos permite preguntarnos por las formas en que se representan los géneros en los espacios de trabajo. O concretamente, cómo se significan las experiencias de los trabajadores de la industria del software a partir de un posicionamiento de género.

Las formas de organización flexible de los equipos de trabajo responden a la interrelación entre programadores con amplia experiencia y posiciones de mando, con programadores junior. Por ejemplo, en Mercado Libre un equipo está conformado por dos o tres desarrolladores junior, el jefe o líder del equipo y el mánager. Luego el sénior mánager es el que dirige varios equipos; sigue el director, y por último, el ceo o dueño de la empresa. En ambas empresas, tanto en Google como en Mercado Libre, se consolida un discurso contundente y embellecido acerca de los beneficios para sus trabajadores y de la «muerte» de la verticalidad en las formas de organizar el trabajo. En ninguna de las dos empresas hay oficinas de trabajadores con puestos de mando; mucho menos «secretarias» para esos mandos. En general, todos comparten el mismo espacio en grandes y largas mesas de trabajo con las mismas condiciones ergonométricas. En ambas empresas, a través de distintas metodologías, es posible tener una charla y/o acercamiento con el ceo ${ }^{13}$.

Lo que nos interesa analizar en este apartado son las formas en que se ejerce la masculinidad en la industria del software y los significados que cobra a partir de las experiencias vividas. La masculinidad, lejos de ser algo con lo que se nace, se aprende en los espacios en los que transitamos. Las imágenes masculinas se han complejizado, se han hecho más variadas, y esto también se refleja en los espacios de trabajo y en la racionalidad instrumental de las políticas empresarias.

13 El ceo de Mercado Libre tiene una metodología de comunicación cuyo análisis amerita otro artículo para realizarse en profundidad. Cada dos meses brinda una conferencia vía plataforma virtual solo para los trabajadores de Mercado Libre de Latinoamérica. En esa conferencia, responde cinco preguntas que los trabajadores realizan a través de la plataforma y que luego son votadas por todos. En Google la metodología de «acercamiento» con los ceos es más «clásica» (si podemos denominarla así), dado que varios de los trabajadores de Sudamérica han viajado a Silicon Valley (EE. UU.), donde se encuentra la central operativa de la empresa. 


\section{«Mimados»y «malcriados»}

Una de las entrevistas que realizamos a un sénior mánager de unos 35 años de la empresa Mercado Libre resultó de lo más elocuente para los propósitos de nuestra investigación. Toda la entrevista transcurrió aproximadamente en una hora, y entre sus manos el sénior mánager siempre sostuvo un spinner, juguete antiestrés muy característico entre jóvenes y/o adolescentes o los llamados millennials. En uno de los pasajes de la entrevista, al preguntarle qué cualidades hay que tener para trabajar en Mercado Libre, nos responde de la siguiente manera:

Imprescindible es el espíritu emprendedor, joven y fresco. Es fundamental el fit cultural, o sea, estar acorde con nuestra cultura, que se basa en trabajar en equipo, ser innovador y estar predispuesto a los desafíos. Y ser talentoso. Acá en Mercado Libre a los que son cracks, los jóvenes talentos, se los mima, se los cuida, porque sabemos que el programador es un recurso limitado y escaso (jefe de equipo de Mercado Libre).

Los sentidos que encierra la expresión «mimar» aparecen en otra entrevista a un ingeniero de la empresa Google:

Pregunta: ¿Cómo es trabajar en Google?

Respuesta: Una empresa que te malcría. En Google tengo mi computadora, mis clases de guitarra... Trabajar en casa me aburre, pero puedo hacerlo si quiero. Es más divertido estar en la oficina. Tenemos toda la tecnología de primera. Te vas malcriando en Google. La silla es la mejor también... Tenés todo. Querés ir al gimnasio, hay un par de máquinas o tenés descuento en Megatlon (ingeniero en Google Analytics, 2017).

Expresiones como «mimar» o ser un «malcriado» cargan con una densidad importante para comprender las relaciones laborales y los perfiles de los trabajadores que se dinamizan en la industria del software. Esta construcción de hombres «mimados» o «malcriados» contrasta notablemente con el aspecto «natural» de la masculinidad, que expresa fortaleza, fuerza, autosuficiencia, etc. $\mathrm{O}$, tal como plantea Norma Fuller (1997), el ejercicio de la masculinidad se diseña en las sociedades occidentales/capitalistas sobre su negativo o lo abyecto: lo femenino. Lo femenino actúa, dirá la autora, como una frontera denigrante de lo masculino, un recordatorio constante de aquello que nos genera rechazo. No obstante, en la industria del software se ejerce un modelo de masculinidad que podemos denominar infantilizada, que no repone la idea de lo abyecto frente a aquellos significantes feminizantes. Muy por el contrario, la construcción de la masculinidad en estos espacios de trabajo acorta las distancias respecto de aquello que 
se conceptualiza como femenino. La noción de «mimado» o «malcriado» remite más a cómo actúa un niño o niña que a un varón masculinizado. Esta noción contrasta brutalmente con los modelos de masculinidad que se dinamizan en otros espacios de trabajo, donde prevalecen nociones más cercanas a la «fortaleza», la «autosubsistencia», el «aguante ${ }^{14} »$.

Como analizamos en el apartado anterior, estos imperativos acerca de la masculinidad en el trabajo desmontan ciertos cánones tradicionales a la vez que mantienen otros. La alusión a ser «mimados»o «malcriados» es recurrente en las empresas de software, a causa de los servicios y/o derechos — muchas veces poco convencionales - que se otorgan: desde gimnasio en las mismas empresas, salones de juego, clases de música y/o yoga, tarjetas corporativas, obras sociales de las más caras, financiamiento y becas para estudiar, convenios con garajes para llegar al trabajo en auto, comidas a bajo coste o incluso sin coste, entre otras varias cuestiones. Siempre hay en las mesas, al menos en Mercado Libre y en Google, comidas a tono con el ambiente «joven» de la empresa: frutas, ensaladas, comidas vegetarianas y snacks. Esto último constituye una interesante metáfora del ambiente «descontracturado»y «liviano» y de los servicios que brindan las empresas a sus trabajadores. No podemos olvidar cierta laxitud respecto de las jornadas de trabajo. La jornada está estipulada en ocho horas de lunes a viernes. No obstante, no hay un control riguroso del cumplimiento horario ${ }^{15}$. Se suma la posibilidad de trabajar en casa - o teletrabajo (Lenguita, 2009) - al menos un día a la semana a elección de los trabajadores. Esta flexibilidad en la jornada laboral — posibilitada por la tecnología - resulta ser uno de los beneficios más reseñados en nuestras entrevistas, que convierte el espacio de trabajo en un lugar que «mima»o «malcría».

\section{Ser «googlin»}

En la empresa Google los trabajadores utilizan recurrentemente un término — «googlin» - para describir cierta actitud joven y emprendedora. «Googlin» es una categoría nativa, algo resbaladiza en su definición, utilizada por los trabaja-

14 Figueroa Perea (2005) investiga las formas de constitución de la masculinidad en establecimientos militares de Latinoamérica. Este tipo de instituciones llevan al extremo las estructuras de relaciones que configuran los modelos de masculinidad operando en la consolidación de un hombre que es capaz de arriesgar hasta su vida, interpelado por el llamado «mito del héroe». También hemos analizado cómo, en la industria petrolera, se maximizan los atributos de la masculinidad patriarcal (Palermo, 2017). En este mismo sentido Laura Caruso (2016) analiza cómo se define la masculinidad «a bordo» en el mundo del trabajo marítimo, donde se potencian valores tales como la fuerza, la virilidad, el coraje y la lucha.

15 Vale aclarar que frecuentemente se trabaja más de las ocho horas estipuladas. Suele suceder que luego de la jornada laboral un trabajador se «conecte» en su casa para completar alguna tarea. 
dores de Google para denominar una actitud sobre todo joven, interesante y un poco extravagante. Así lo describe un trabajador de Google:

En términos de actitud, es una actitud un poco que tiene un aspecto medio lúdico. Siempre la gente de ahí algún tipo de historia interesante tiene, que es como que está en su narrativa de googlin, entendés, como, qué sé yo, tenés alguno que haya sido campeón de una olimpiada de matemática, otro que haya corrido una carrera de montaña... No sé, cualquier cosa medio así como delirante que lo pone en una narrativa personal de ser una persona creativa, proactiva, ingeniosa (ingeniero en Google Analytics. 2017).

Ser «googlin» redunda en un perfil de trabajador joven, que debe ser interesante y creativo. Tal como plantea Gustavo Lins Ribeiro: «En este medio [...] hay una tendencia a creer que cuanto más joven sea la persona, más capaz será de innovar» $(2017: 26)$. No obstante, la juventud es un valor en la consolidación de la disciplina fabril que no necesariamente está anclado a la edad vital: es una actitud. El otro atributo es el carácter lúdico, que atraviesa constantemente la idea de «googlin» y que indefectiblemente esto asociada a la creatividad. La creatividad es la fuente de innovación en esta industria, y el trabajo debe ser tomado con espíritu lúdico. La autocrítica y la actitud de superación son valores fundamentales. La asociación de las tareas en el software con lo divertido resulta ser una constante en estos espacios de trabajo: atributos exigidos e interpelados para ejercer la labor en estas empresas y en particular la tarea de desarrollador. Es por ello que se configura un nuevo ethos que en más de una ocasión confunde la vida con el empleo, generando espacios de trabajo lúdicos y atractivos.

Así lo detallaba un ex sénior mánager de Mercado Libre:

Yo remarco el fit cultural que hay que tener para entrar a trabajar... Es un tema que es como, hay un tema de piel, es como que tenés que tener determinada buena onda, tenemos que poder decir que tenés determinada buena onda que sentimos que, no sé, que te gusta trabajar en mi equipo, que sos receptivo a las críticas constructivas. $\mathrm{O}$ sea, nosotros trabajamos muy autocríticos entonces, es como que si vemos que alguien se pone medio a la defensiva en la entrevista al toque es como que es una bandera roja. Decimos: che, esto no va a andar bien porque nosotros no estamos, estamos todo el tiempo, se labura de una manera tan dinámica acá adentro que todos tienen que tener la capacidad de ser críticos... Como cuando jugás: si no sabés recrearte en un juego te volvés repetitivo y obsoleto (ex sénior mánager, Mercado Libre, 2017).

Vuelve a surgir en esta entrevista la idea de trabajar jugando. En este sentido, para entrar a estas empresas es necesario el fit cultural. Noción que redunda en 
un trabajador con los atributos requeridos en estos procesos de trabajo donde la tecnología se constituye como un factor central. El trabajo se resignifica de forma extraña, al menos desde la mirada del investigador, en relación con las actividades lúdicas. Quizá el fetichismo de la tecnología resignifique la descripción del trabajo como juego.

No obstante, cuando indagamos un poco más sobre estos imperativos de masculinidad, la imagen de trabajar jugando se relativiza:

Cuando querés irte porque no das más de la cabeza, se te genera una contradicción con esa sensación de que como estás en un lugar tan idílico espacialmente y laboralmente, no podés irte. También te viene de afuera «che, qué bueno que estás en Google». Ahí te empieza a pegar como que el que está mal soy yo, no es este sistema o esto que me está generando esta incomodidad. Tiene esa parte de autoflagelo que se da bastante. Por charlas con amigos que siguen ahí bancándose la presión porque dejar Google es todo un tema (extrabajador de Google, 2017).

El desgaste psíquico en los trabajadores es sin lugar a dudas uno de los grandes problemas de estos espacios de trabajo. Algunos de los que hemos entrevistado abandonaron el trabajo o están pensando en hacerlo. Renunciar a un contexto laboral representado como «idílico» o «lúdico» resulta ser una decisión por demás difícil de tomar.

Marta Lamas (1994) nos recuerda que las fronteras de género y clase (categorías inseparables) son a menudo móviles y elásticas y que el lenguaje específico en cuanto al género influye en cómo se piensan o se dicen las cosas. En tal sentido, es posible afirmar que detrás de estas nociones genéricas acerca del trabajo se consolidan nociones próximas a la idea de «hombres adolescentes», a una «masculinidad infantilizada» particularmente en las nociones de «mimados» y/o «malcriados».

\section{Consideraciones finales}

El debate sobre el capitalismo cognitivo abre innumerables puertas de entrada para diversos análisis. Evidentemente nos encontramos en un momento del desarrollo del capitalismo que afecta a la forma en que el capital es dotado de valor, y en cierta forma las fábricas de software se encuentran en el centro de la escena de este proceso. No obstante, es necesario evitar análisis acalorados que planteen el fin de determinadas etapas o el advenimiento de otras sin poder observar profundas continuidades $-y$ rupturas también - en las formas en que el capital se valoriza. El control del tiempo sigue siendo un factor determinante tanto en 
el pasado como en el presente y el futuro. Sin embargo, queda claro que, dadas las características del proceso productivo, donde la creatividad es el motor, no es posible aplicar las viejas recetas de gerenciamiento rígidas e inflexibles. En tal sentido, se despliega toda una estrategia empresarial orientada a producir y reproducir una fuerza de trabajo acorde con los intereses de la producción. Este último planteamiento de cómo es esa fuerza de trabajo y cuáles son los imperativos a los que están expuestos constituye un interrogante en la actualidad poco investigado. La capacidad de trabajar no brota de forma «natural» sino que debe ser socialmente producida. Y en tal sentido, se interpela un particular ethos de la masculinidad que desmonta ciertos elementos de un modelo patriarcal, pero no en el sentido de la liberación del colectivo de trabajo, sino para fortalecer una determinada disciplina fabril.

Comprender que existen diversas formas de ejercer la masculinidad fue uno de los aportes de los estudios sobre masculinidades. Ahora bien, lo que podemos presentar como hallazgo desde los estudios del trabajo es que las políticas empresarias en la industria del software, a partir de la necesidad de consolidar los atributos de una disciplina fabril, operan en la afirmación de construcciones genéricas alejadas de los modelos tradicionales. Archetti nos recuerda que la masculinidad es un proceso de tensión y negociación constante en función de los modelos exitosos de cómo ser hombres (1999: 157). En la industria vinculada a la producción de bienes informacionales, el modelo exitoso de hombre se vincula indisociablemente con la idea de juventud, de una actitud de un joven «malcriado», «mimado» $\mathrm{o}$ «googlin». Estos atributos de la masculinidad trastocan ciertos valores tradicionales y/o patriarcales. No obstante, consolidan prácticas y representaciones acordes a una disciplina fabril que no deja exentos a los varones de diversos sufrimientos.

Aún nos faltan hondas reflexiones para problematizar de forma más profunda la relación entre masculinidad(es) y trabajo. Lo que sí queda claro es que las políticas empresarias consolidan posiciones de género con una racionalidad instrumental orientada a producir $y$ reproducir una fuerza de trabajo. 


\section{Bibliografía}

Achilli, E. L. (2005). Investigar en antropología. Los desafíos de trasmitir un oficio. Laborde Libreos Editor.

Archetti, Eduardo (1999). Masculinidades. Fútbol, tango y polo en la Argentina. Argentina, Editorial Antropofagia.

BAstos, Santiago (1998). «Desbordando patrones: el comportamiento doméstico de los hombres», La Ventana, n. ${ }^{\circ}$ 7, pp. 166-224.

Braverman, Harry (1974). Trabajo y capital monopolista. México, Nuestro Tiempo.

BeLl, Daniel (1976). El advenimiento de la sociedad pos industrial. Madrid, Alianza Editorial.

Bourdieu, Pierre (2012). La dominación masculina. Barcelona, Anagrama.

Caruso, Laura (2016). «Hombres a bordo: experiencia laboral y masculinidades en el mundo del trabajo marítimo en la primera posguerra». En Andújar, Andrea; Caruso, Laura; Gutiérrez, Florencia; Palermo, Silvana y Schettini, Cristiana (comps.). Vivir con lo justo. Estudios de bistoria social del trabajo en perspectiva de género, Argentina, siglo XIX y XX. Rosario, Prohistoria, pp. 63-81.

Castells, Manuel (2006) [1997]. La era de la información. Tomo 1, México DF, Editorial Siglo XXI.

Castillo, Juan José (2007). El trabajo fluido en la sociedad de la información: organización y división del trabajo en las fábricas de software. Madrid, Miño y Dávila.

Connell, Robert W. (1995). Masculinities. Berkeley, University of California Press.

Coriat, Benjamin (1991). Pensar al revés. Trabajo y organización en la empresa japonesa. Francia, Siglo XXI Editores.

Dughera, Lucila; Segura, Agustín; Yansen, Guillermina y Zukerfeld, Mariano (2012). «Las técnicas de los trabajadores informáticos. El rol de los aprendizajes formales, no formales e informales en la producción del software». En Dughera Lucila; Yansen, Guillermina y Zukerfeld, Mariano (comps.). Gente con códigos. La heterogeneidad de los procesos productivos de software. Buenos Aires, Argentina, Universidad Maimónides, Editorial Científica y Literaria, pp. 165-207.

Erbes, Analía; Robert, Verónica y Yoguel, Gabriel (2004). «El sendero evolutivo y potencialidades del sector del software en Argentina». En Borrelo, José; Robert, Verónica y Yoguel, Gabriel (comps.). La informática en Ar- 
gentina. Desafíos a la especialización y la competitividad. Buenos Aires, UNGS, Editorial Prometeo.

Feropozzi, Hugo y Zukerfeld, Mariano (2012). «¿Puede el sindicalismo adaptarse al trabajo informacional? Un análisis de la relación entre los trabajadores informáticos y el mundo gremial». En Dughera, Lucila; Yansen, Guillermina y Zukerfeld, Mariano (comps.). Gente con códigos. La heterogeneidad de los procesos productivos de software. Buenos Aires, Argentina, Universidad Maimónides, Editorial Científica y Literaria, pp. 279-323.

Figueroa Perea, Juan Guillermo (2005). «Elementos para el estudio de la sexualidad y la salud de los varones integrantes de las Fuerzas Armadas». En Pantelides, Edith Alejandra y López, Elsa (comps.). Varones Latinoamericanos. Buenos Aires, Paidós, pp. 47-80.

Fuller, Norma (1997). «Fronteras y retos: Varones de clase media del Perú». En Valdés, Teresa y Olavarría, José (ed.). Masculinidad/es. Poder y crisis. Santiago de Chile, Isis Internacional, pp. 139-153.

Gilmore, David (1994). Hacerse hombre: concepciones culturales de la masculinidad. Barcelona, Paidós.

Guber, R. (2001). La etnografía: Método, campo y reflexividad. Buenos Aires, Norma.

Kazandjian, Robert (2017). «Desempeñar la masculinidad». En No nacemos machos. Cinco ensayos para repensar el ser hombre en el patriarcado. Ciudad de México, Ediciones La Social, pp. 15-23.

Kimmel, Michael (1997), "Rethinking "Masculinity": New Directions in Research». En Kimmel, Michael (ed.). Changing Men: New Directions in Research on Men and Masculinity. Newbury Park CA, Sage, pp. 9-24.

Kosı́, Karel (1967). Dialéctica de lo concreto. México, Editorial Grijalbo.

Lamas, Marta (1994). «Cuerpo: diferencia sexual y género». Debate Feminista, n. ${ }^{\circ} 10$, septiembre, México, pp. 3-31.

Laqueur, Thomas (1994). La construcción del sexo. Barcelona, Cátedra.

Lenguita, Paula (2009). «Las formas disciplinarias del teletrabajo en el periodismo gráfico». Revista Theomai, n. ${ }^{\circ}$ 19, Quilmes, Argentina, pp.75-95. Disponible en: <http://revista-theomai.unq.edu.ar/numero19/ArtLenguita.pdf $>$.

Lins Ribeiro, Gustavo (2017). «El precio de la palabra: la hegemonía del capitalismo electrónico-informático y el googleísmo». Desacatos, n. ${ }^{\circ} 56$, México, pp. 16-33.

Míguez, Pablo (2010). «Automatización y revolución informática. Los cambios en el proceso de trabajo y sus efectos en el trabajo». En Montes Cató, Juan 
(comp.). El trabajo en el capitalismo informacional. Los trabajadores en la industria del software. Benavidez, Poder y Trabajo Editores, pp. 39-69.

Mochi Alemán, P. (2003). «Los modelos de organización de la empresa de software: paradigma de la empresa posfordista». En 4 Congreso Latinoamericano de Sociología del trabajo, La Habana, Cuba.

Montes Cató, Juan (2010). «Condiciones de explotación y fuerza de trabajo en la industria del software». En Montes Cató, Juan (comp.). El trabajo en el capitalismo informacional. Los trabajadores en la industria del software. Benavidez, Poder y Trabajo Editores, pp. 69-101.

Mura, Nahuel; Yansen, Guillermina; Zukerfeld, Mariano (2012). «iPor qué las mujeres no programan? Acerca de los vínculos entre género, tecnología y software». En Dughera, Lucila; Yansen, Guillermina y Zukerfeld, Mariano (comps.). Gente con códigos. La heterogeneidad de los procesos productivos de software. Buenos Aires, Argentina, Universidad Maimónides, Editorial Científica y Literaria, pp. 237-278.

Palermo, Hernán M. (2012). Cadenas de oro negro en el esplendor y ocaso de YPF. Buenos Aires, Antropofagia.

Palermo, Hernán M. (2017). La producción de la masculinidad en el trabajo petrolero. Buenos Aires, Editorial Biblos.

Schiller, Dan (2000). Digital Capitalism. Networking the Global Market System. MIT Press Cambridge.

Sсотт, Joan W. (2008). «El géneroः una categoría útil para el análisis histórico». En Lamas, Marta (comp.). El género: la construcción cultural de la diferencia sexual. México, PUEG, pp. 265-302. [(1986) «Gender: A Useful Category of Historical Analysis», en American Historical Review, n. ${ }^{\circ}$ 91, pp. 1.053-1.075]. Zukerfeld, Mariano (2012). «Una introducción al sector información y al trabajo informacional». En Dughera, Lucila; Yansen, Guillermina y ZukerFeld, Mariano (comps.). Gente con códigos. La heterogeneidad de los procesos productivos de software. Buenos Aires, Argentina, Universidad Maimónides, Editorial Científica y Literaria, pp. 25-87. 